\title{
Congenital myasthenia-related AChR $\delta$ subunit mutation interferes with intersubunit communication essential for channel gating
}

\author{
Xin-Ming Shen, ${ }^{1}$ Taku Fukuda, ${ }^{1}$ Kinji Ohno, ${ }^{1}$ Steven M. Sine, ${ }^{2}$ and Andrew G. Engel ${ }^{1}$ \\ ${ }^{1}$ Muscle Research Laboratory, Department of Neurology, ${ }^{2}$ Receptor Biology Laboratory, Department of Physiology and Biomedical Engineering, \\ and Department of Neurology, Mayo Clinic, Rochester, Minnesota, USA.
}

\begin{abstract}
Congenital myasthenias (CMs) arise from defects in neuromuscular junction-associated proteins. Deciphering the molecular bases of the CMs is required for therapy and illuminates structure-function relationships in these proteins. Here, we analyze the effects of a mutation in 1 of 4 homologous subunits in the AChR from a CM patient, a Leu to Pro mutation at position 42 of the $\delta$ subunit. The mutation is located in a region of contact between subunits required for rapid opening of the AChR channel and impedes the rate of channel opening. Substitutions of Gly, Lys, or Asp for $\delta$ L42, or substitutions of Pro along the local protein chain, also slowed channel opening. Substitution of Pro for Leu in the $\varepsilon$ subunit slowed opening, whereas this substitution had no effect in the $\beta$ subunit and actually sped opening in the $\alpha$ subunit. Analyses of energetic coupling between residues at the subunit interface showed that $\delta \mathrm{L} 42$ is functionally linked to $\alpha \mathrm{T} 127$, a key residue in the adjacent $\alpha$ subunit required for rapid channel opening. Thus, $\delta \mathrm{L} 42$ is part of an intersubunit network that enables ACh binding to rapidly open the AChR channel, which may be compromised in patients with CM.
\end{abstract}

\section{Introduction}

Congenital myasthenias (CMs) are inherited disorders caused by defects in neuromuscular junction-associated proteins (1). These include choline acetyltransferase (2); the collagenic tail subunit of endplate (EP) acetylcholinesterase (AChE) $(3,4)$; the AChR (5); the cytoplasmic protein rapsyn, which concentrates $A C h R$ at the crests of the junctional folds (6); the muscle-specific receptor tyrosine kinase (MuSK) (7), which activates rapsyn; the muscle-intrinsic activator of MuSK known as Dok-7 (8); and the $\mathrm{Na}_{\mathrm{v}} 1.4$ sodium channel in the troughs of the folds (9). Most postsynaptic CMs are caused by mutations in different subunits of AChR that alter its kinetic properties, reduce its expression, or both.

The AChR is a ligand-gated ion channel in which 5 homologous subunits align side by side to form a cylinder lodged in the cell membrane. At the innervated adult EP, the stoichiometry of the subunits is $\alpha_{2} \beta \delta \varepsilon$, while at denervated or developing EPs, the fetal $\gamma$ subunit is present in place of the $\varepsilon$ subunit. Each subunit includes 1 large extracellular domain and 4 transmembrane domains (10). The extracellular domain consists of an inner core of $6 \beta$ strands and an outer shell of $4 \beta$ strands, whereas the transmembrane domains are $\alpha$-helices (11). The 2 ligand binding sites are formed by specialized regions of the extracellular domains, where the $\alpha$ subunits juxtapose the $\delta$ and $\varepsilon$ subunits. At the junction of the ligand binding and transmembrane domains, the $\beta$ strands of the extracellular domain merge with the tops of the $\alpha$-helices of the transmembrane domain to form a structural transition zone (Figure 1). In the $\alpha$ subunit, this transition zone couples structural changes due to agonist binding into opening of the channel (12).

Nonstandard abbreviations used: $\alpha$-bgt, $\alpha$-bungarotoxin; CM, congenital myasthenia; EP, endplate; EPP, EP potential; MEPC, miniature EP current; MEPP miniature EPP; $\mathrm{P}_{\text {open }}$, channel open probability.

Conflict of interest: The authors have declared that no conflict of interest exists. Citation for this article: J. Clin. Invest. 118:1867-1876 (2008). doi:10.1172/JCI34527.
While substantial evidence shows that this intrasubunit transition zone couples agonist binding with channel opening (reviewed in refs. 13,14 ), less is known about how the $2 \alpha$ subunits interact with adjacent subunits to enable channel opening. A recent study, however, demonstrated a functional linkage essential for channel opening between $Y 127$ in the $\alpha$ subunits and A41 in the $\delta$ subunit and the equivalent $\mathrm{A} 39$ in the $\varepsilon$ subunit (15). Whether other residues of the $\delta$ and $\varepsilon$ subunits contribute to the intersubunit link is not known, and to date no naturally occurring mutations have been detected in any intersubunit link of the AChR.

We here trace the cause of CM to 2 heteroallelic mutations in genes encoding the AChR $\delta$ subunit, $\delta$ I58K and $\delta$ L42P. We find that $\delta \mathrm{I} 58 \mathrm{~K}$ prevents expression of the AChR on the cell surface, whereas $\delta$ L42P permits expression but causes abnormally brief channel openings, thus determining the phenotype. We show that the principal effect of $\delta \mathrm{L} 42 \mathrm{P}$ is to reduce the rate of opening of the AChR channel, reducing its gating efficiency. Although the other AChR subunits contain Leu at positions equivalent to $\delta 42$, substitution of Pro for the equivalent Leu in the $\alpha$ subunit augments rather than impedes channel gating, whereas substitution in the $\beta$ subunit has no effect, demonstrating that $\delta \mathrm{L} 42$ contributes to channel gating in a subunit-specific manner. Finally, we show that the functional consequences of $\delta$ L42P depend on $\alpha \mathrm{Y} 127$ of the juxtaposed $\alpha$ subunit, indicating that the mutation hinders an intersubunit interaction essential for efficient gating.

\section{Results}

Characteristics of CM syndrome patient. A 20-year-old woman had moderately severe to severe myasthenic symptoms since birth, no anti-AChR antibodies, and a 34\%-71\% decremental response of the compound muscle action potential on repetitive stimulation of motor nerves at $2 \mathrm{~Hz}$. She responded poorly to pyridostigmine alone but improved markedly after the addition of 3,4-diaminopyridine. A similarly affected sibling died at age 11 months. 


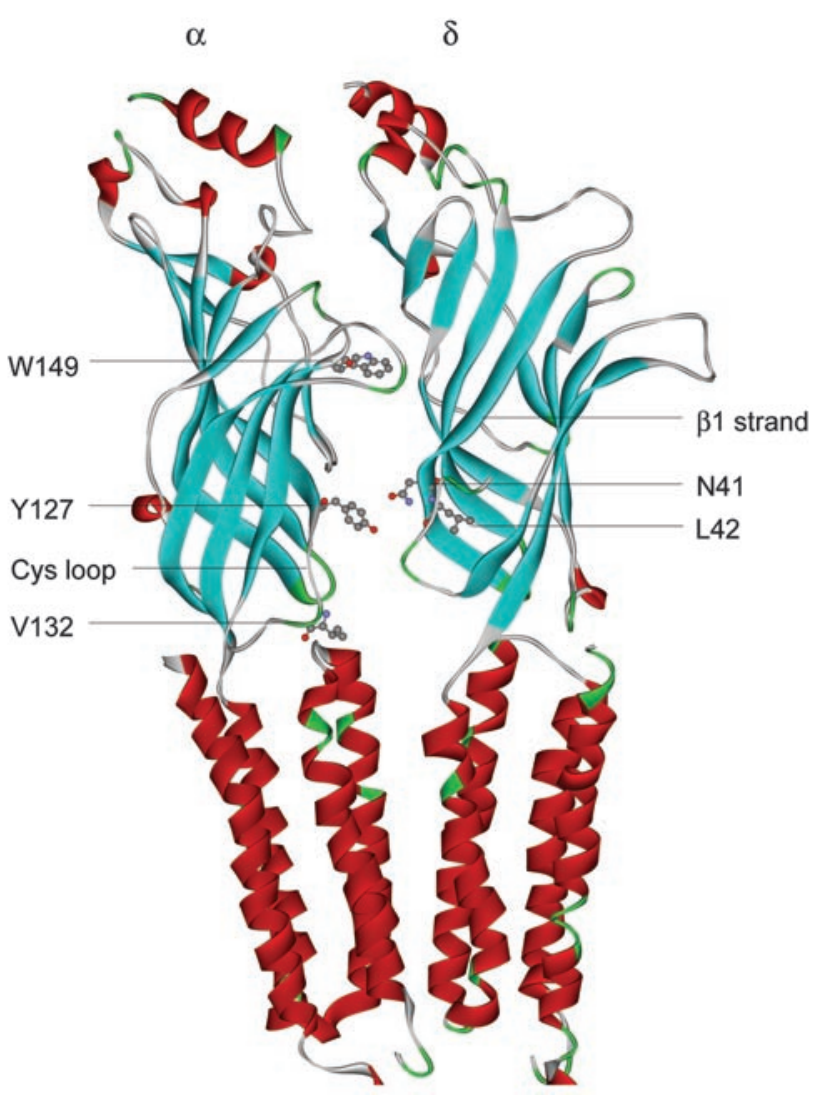

EP studies. The configuration of the EPs, evaluated from the cytochemical reaction for ACh on longitudinally oriented teased single muscle fibers, was abnormal, with numerous small EP regions distributed over a 2- to 4-fold increased span of the muscle fiber surface (Figure 2), in contrast to the typical pretzel-shaped distribution. The reaction for $\mathrm{AChR}$, detected in cryostat sections with rhodaminelabeled $\alpha$-bungarotoxin $(\alpha$-bgt) was greatly attenuated.

On EM, the structural integrity of the junctional folds was preserved. Morphometric analysis of individual EP regions revealed that the nerve terminals were of normal size but the postsynaptic area and membrane length were smaller than normal. The reaction for AChR, detected with peroxidase-labeled $\alpha$-bgt, was patchy and attenuated (Figure 3) and the AChR-reactive postsynaptic membrane length was markedly reduced (Table 1 ). The number of [ $\left.{ }^{125} \mathrm{I}\right]$ $\alpha$-bgt sites per EP was decreased to $16 \%$ of normal (Table 2 ). In vitro microelectrode studies of intercostal muscle EPs showed that quantal release by nerve impulse was normal. The miniature EP potential (MEPP) and current (MEPC) amplitudes were reduced to $6 \%$ and $10 \%$ of normal, respectively (Table 2 ).

Mutation analysis. To determine the molecular basis of the phenotypic abnormalities, we sequenced each AChR subunit gene. This

\section{Figure 1}

Structural model of extracellular and transmembrane domains of the AChR $\alpha$ and $\delta$ subunits (Protein Data Bank code 2BG9). $\alpha$ W149 is at the center of the ligand binding site. In the transition zone, the indicated N41 and L42 residues are in the $\beta_{1}$ strand of the $\delta$ subunit. $\delta N 41$ is near Y127 in the $\alpha$ subunit.

revealed 3 heterozygous mutations in the $\delta$ subunit gene CHRND: $125 \mathrm{~T} \rightarrow \mathrm{C}$, predicting a Leu to Pro mutation at codon $42(\delta \mathrm{L} 42 \mathrm{P})$ in the $\beta_{1}$ strand of the subunit; $173 \mathrm{~T} \rightarrow \mathrm{A}$, predicting an Ile to Lys mutation at codon $58(\delta \mathrm{I} 58 \mathrm{~K})$ in the $\beta_{2}$ strand; and $277 \mathrm{G} \rightarrow \mathrm{C}$, predicting a Val to Leu mutation at codon $93(\delta \mathrm{V} 93 \mathrm{~L})$ in the $\beta_{4}$ strand (Figure $\left.4 \mathrm{~A}\right)$. $\delta \mathrm{L} 42$ and $\delta \mathrm{V} 93 \mathrm{~L}$ are conserved across AChR $\delta$ subunits of different species; I58 is conserved in $\delta$ subunits of mammals and in human $\varepsilon$ and $\gamma$ subunits (Figure 3A). None of the mutations was present in 200 normal alleles of 100 unrelated subjects. Family analysis indicated that each mutation was recessive; the paternal allele harbored $\delta 158 \mathrm{~K}$ and $\delta \mathrm{V} 93 \mathrm{~L}$; the maternal allele harbored $\delta \mathrm{L} 42 \mathrm{P}$ (Figure 4B).

Expression studies in HEK cells. To assess pathogenicity of the observed mutations, we engineered each mutation into the human $\delta$ subunit and cotransfected cDNAs encoding either mutant or wild-type $\delta$ subunits with complimentary wild-type $\alpha, \beta$, and $\varepsilon$ subunits in HEK cells. To assess expression of the AChR on the cell surface, we measured binding of $\left[{ }^{125} \mathrm{I}\right] \alpha$-bgt to intact cells (Figure 5). Compared with the wild-type AChR, expression was slightly enhanced by $\delta$ V $93 \mathrm{~L}$ but was reduced to $37 \%$ by $\delta \mathrm{L} 42 \mathrm{P}$ and to $5 \%$ by $\delta I 58 \mathrm{~K}$. We also omitted the $\delta$ subunit cDNA from the transfection and measured $\alpha$-bgt binding. The resulting $\delta$-omitted receptors $\left(\alpha_{2} \beta \varepsilon_{2}\right)$ yielded $5 \%$ of the wild-type binding capacity, indicating $\delta \mathrm{I} 58 \mathrm{~K}$ was a null mutation (Figure $5 \mathrm{~A}$ ). Surface expression of the double mutant $\delta \mathrm{I} 58 \mathrm{~K}+\mathrm{V} 93 \mathrm{~L}$ AChR was similar to that of the $\delta I 58 \mathrm{~K} A C h R$, indicating $\delta \mathrm{V} 93 \mathrm{~L}$ did not mitigate the effects of $8 \mathrm{I} 58 \mathrm{~K}$ (Figure $5 \mathrm{~A})$.

To gain further insight into why $\delta I 58 \mathrm{~K}$ prevents AChR expression, we monitored the ability of the mutant $\delta$ subunit to form a complex with the wild-type $\alpha$ subunit. Compared with the total toxin-binding capacity of the wild-type $\alpha \delta$ dimer expressed in HEK cells, the capacity of cells expressing the mutant dimer was reduced to $15 \%$. This reduced capacity was similar to that obtained for HEK cells expressing only the wild-type $\alpha$ subunit (Figure 5B), indicating that $\delta I 58 \mathrm{~K}$ either prevents association of the $\alpha$ and $\delta$ subunits, an early step in assembly of the pentameric receptor (16), or that the $\delta$ subunit harboring $I 58 \mathrm{~K}$ is not expressed.

Activation kinetics of the $\delta L 42 P$ mutant. The safety margin of neuromuscular transmission depends crucially on the ability of nervereleased ACh to rapidly and efficiently activate AChR channels. To determine whether $\delta \mathrm{L} 42 \mathrm{P}$ or $\delta \mathrm{V} 93 \mathrm{~L}$ affect the kinetics of $\mathrm{AChR}$ activation, we recorded single channel currents elicited by a limit-

\section{Figure 2}

Acetylcholinesterase-reactive EP regions. Note dispersion of EP regions over an extended length of the muscle fiber. Scale bar: $20 \mu \mathrm{m}$.

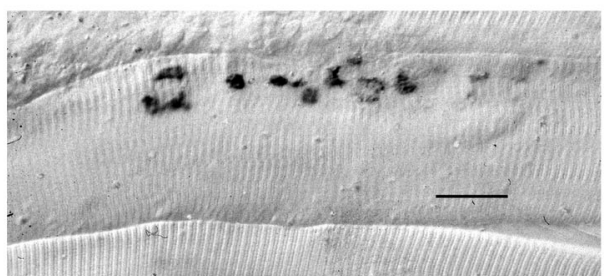



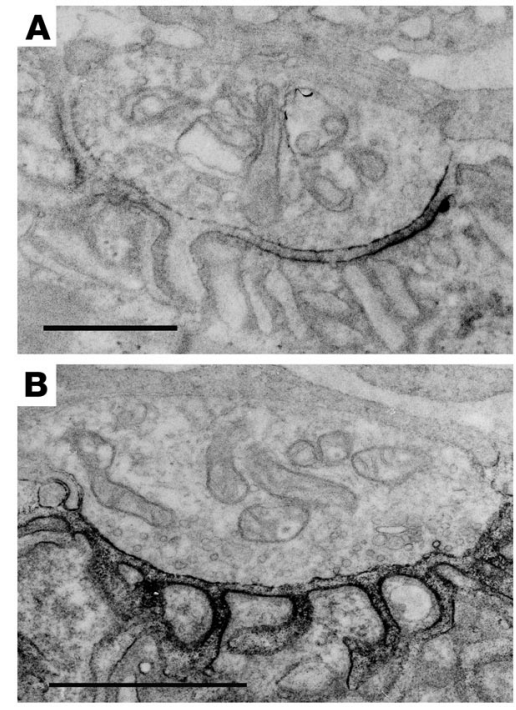

ing low concentration of ACh $(50 \mathrm{nM})$ from HEK cells expressing wild-type or mutant AChRs (Figure 6). The resulting channel openings appeared either as isolated openings or as several openings in quick succession, called bursts, the durations of which provide an indirect measure of the rate of decay of the postsynaptic current. After constructing duration histograms of the bursts and fitting sums of exponentials to them, we found 2 components of bursts for the $\delta$ L $42 \mathrm{P} A C h R$ and 3 components for the wild-type AChR (Figure 6). For the $\delta \mathrm{L} 42 \mathrm{P} A C h R$, the mean duration of the longest component of bursts was $0.76 \mathrm{~ms}$, much briefer than the corresponding value of $3.3 \mathrm{~ms}$ for the wild-type AChR, while that of the $\delta \mathrm{V} 93 \mathrm{~L}$ AChR was mildly prolonged (Table 3 ). Because $\delta I 58 \mathrm{~K}$ is a null mutation and $\delta \mathrm{V} 93 \mathrm{~L}$ is not pathogenic, $\delta \mathrm{L} 42 \mathrm{P}$ determined the phenotype, which resulted from a change in one or more elementary steps in the activation process.

To identify elementary kinetic steps in AChR activation altered by the $\delta$ L42P mutant, we recorded single-channel currents over a range of ACh concentrations and constructed histograms of the resulting open and closed dwell times (see Methods). For both wild-type and $\delta$ L42P AChRs, the closed-duration histograms exhibited several exponential components that shifted from long to brief durations, with increasing ACh concentrations (Figure 7, A and B). However, for the $\delta \mathrm{L} 42 \mathrm{P}$ AChR, the shift toward brief closed durations was significantly less, and at a saturating concentration of ACh, closed durations remained prolonged. For both AChRs, the ACh-dependent shift toward brief closed durations is a hallmark of a process driven by binding of ACh. However, for the $\delta \mathrm{L} 42 \mathrm{P} \mathrm{AChR}$, the prolonged closed durations at a saturating concentration of ACh indicated a significant slowing of the final isomerization step that opened the channel. Open-duration histograms changed little across the range of ACh concentrations but were uniformly briefer for the $\delta \mathrm{L} 42 \mathrm{P}$ mutant than for the wild-type AChR, indicating that the mutation destabilized the open state.

To quantify changes in elementary rate constants underlying activation of the $8 \mathrm{~L} 42 \mathrm{P} A C h R$, we fitted a scheme (Figure 8) to the single-channel closed and open dwell times elicited by the entire range of ACh concentrations displayed in Figure 7. This scheme depicts AChR activation as the reversible binding of 2 molecules of agonist

\section{Figure 3}

EM localization of AChR with peroxidase-labeled $\alpha$-bgt at patient (A) and control (B) EPs. Scale bars: $1 \mu \mathrm{m}$.

to the AChR in the resting, closed state, followed by reversible formation of the open state. At high concentrations, ACh blocks the open channel to form a nonconducting blocked state.

For both wild-type and mutant $\delta$ L42P AChRs, probability density functions computed from the fitted rate constants describe the dwell time distributions for the entire range of ACh concentrations. The analysis provides estimates of rate constants for ACh association and dissociation and opening and closing of the channel (Table 4). The most significant effects of $\delta \mathrm{L} 42 \mathrm{P}$ were an 8 -fold decrease of the channel opening rate constant and a 1.4-fold increase of the channel closing rate constant; the ratio of the 2 rate constants gives the diliganded channel gating equilibrium constant $\theta_{2}$, which decreases 12.5 -fold, indicating reduced gating efficiency.

Rate constants underlying ACh association and dissociation were modestly affected by the mutation, with rate constants for ACh dissociation $\left(k_{-1}\right.$ and $\left.k_{-2}\right)$ slowed, suggesting modest enhancement of ACh affinity. Although the estimate of $k_{-2}$ was well defined, the estimate of $k_{-1}$ showed a larger error, preventing a concrete conclusion regarding a change in ACh affinity.

The fitted rate constants in Table 4 allow calculation of the channel open probability $\left(\mathrm{P}_{\mathrm{open}}\right)$ as a function of ACh concentration. For the $\delta \mathrm{L} 42 \mathrm{P}$ receptor, the $\mathrm{P}_{\text {open }}$ increased more gradually and plateaued at a lower ACh concentration than for the wild-type AChR (Figure 7C). The fitted rate constants in Table 4 can be used to predict the mean duration of bursts according to $\left(1+\beta_{2} / k_{-2}\right) / \alpha_{2}$; this yields a value of $0.7 \mathrm{~ms}$, which agrees closely with the independently determined burst duration of $0.76 \mathrm{~ms}$ recorded in presence of $50 \mathrm{nM}$ ACh (Table 3). The decrease of the burst duration predicts an abnormally fast decay of synaptic currents typical of the fast-channel myasthenic syndrome (1). The fitted rate constants also predict the probability that a diliganded channel will open following an impulse of nerve-released ACh according to $\beta_{2} /\left(\beta_{2}+k_{-2}\right)$, which returns a value of 0.84 for the wild-type AChR and 0.53 for the $\delta \mathrm{L} 42 \mathrm{P} A C h R$, predicting a reduced peak of the synaptic response.

To summarize, patch-clamp analyses of the kinetic properties of the $\delta$ L42P AChR reveal reduced gating efficiency, abnormally

\section{Table 1}

Morphometric analysis of EP regions

\begin{tabular}{lcc} 
Parameter & \multicolumn{1}{c}{ Patient } & \multicolumn{1}{c}{ Controls } \\
Nerve terminal area $\left(\mu \mathrm{m}^{2}\right)$ & $3.28 \pm 0.40(27)$ & $3.88 \pm 0.39(63)$ \\
Postsynaptic area $\left(\mu \mathrm{m}^{2}\right)$ & $6.13 \pm 0.42^{\mathrm{A}}(27)$ & $10.60 \pm 0.79(39)$ \\
$\quad \begin{array}{l}\text { Normalized postsynaptic } \\
\quad \text { membrane length }\left(\mu \mathrm{m} / \mu \mathrm{m}^{2}\right)^{\mathrm{B}}\end{array}$ & $4.07 \pm 0.20^{\mathrm{A}}(27)$ & $5.83 \pm 0.25(47)$ \\
$\quad \begin{array}{l}\text { Normalized AChR-reactive } \\
\quad \text { membrane lengthC }\end{array}$ & $1.00 \pm 0.13^{\mathrm{A}}(16)$ & $3.01 \pm 0.11(85)$ \\
\end{tabular}

Values indicate mean \pm SEM; numbers in parentheses represent number of EP regions. More than one region can occur at an EP. ${ }^{A} P<0.001$. BCalculated as postsynaptic membrane length divided by postsynaptic area. ${ }^{C}$ Calculated as AChR-reactive postsynaptic membrane length $(\mu \mathrm{m})$ divided by length of primary synaptic cleft $(\mu \mathrm{m})$. 


\section{Table 2}

In vitro microelectrode and $\alpha$-bgt binding studies

$\begin{array}{lcc}\text { Parameter } & \text { Patient } & \text { Controls } \\ m^{\mathrm{A}} & 32 \pm 5(17) & 31 \pm 1(190) \\ \text { MEPP amplitude }(\mathrm{mV})^{\mathrm{B}} & 0.067 \pm 0.011(17) & 1.00 \pm 0.025(165) \\ \text { MEPC amplitude }(\mathrm{nA})^{\mathrm{C}} & 0.44 \pm 0.064(11) & 3.95 \pm 0.10(79) \\ \text { [125I] } \alpha \text {-bgt binding } & 2.06 \times 10^{6} & 12.82 \pm 0.79 \times 10^{6}(13) \\ \quad \text { sites/EP } & & \end{array}$

Values indicate mean \pm SEM. Measurements were taken at $29 \pm 0.5^{\circ} \mathrm{C}$ for MEPP and EPP recordings and at $22 \pm 0.5^{\circ} \mathrm{C}$ for MEPC recordings. Numbers in parenthesis indicate number of subjects for $\left[{ }^{125} \mid\right] \alpha$-bgt binding sites/EP and number of EPs for other measurements. ${ }^{A} m$ is the quantal content of the EPP at $1 \mathrm{~Hz}$ stimulation corrected for resting membrane potential of $-80 \mathrm{mV}$, nonlinear summation, and non-Poisson release. ${ }^{B}$ Estimated by dividing the corrected EPP amplitude by $m$ and correcting for a fiber diameter of $50 \mu \mathrm{m}$. CEstimated by dividing the EP current amplitude by $m$.

brief channel opening events, and a decreased probability that the channel will open in response to nerve-released ACh.

Other substitutions of $\delta L 42 . \delta L 42 \mathrm{P}$ introduces a Pro residue in the lower third of its constituent $\beta_{1}$ strand (Figure 1 ). The $\beta_{1}$ strand is part of an antiparallel $\beta$ sheet stabilized by interstrand hydrogen bonds, and introduction of a Pro prevents formation of 1 interstrand hydrogen bond. To determine whether the mutation effects were Pro-specific, and thus the result of removal of a hydrogen bond, we replaced the Leu in $\delta$ codon 42 by a small and flexible Gly and the oppositely charged residues Lys and Asp (all 3 mutations enable formation of interstrand hydrogen bonds). For each mutation, bursts of channel openings were abnormally brief (Table 3), and the channel gating equilibrium constant was decreased 12- to 25-fold, mainly due to decrease of the channel opening rate constant $\beta_{2}$ (Table 4$)$. Thus, the attenuated gating by $\delta \mathrm{L} 42 \mathrm{P}$ was not Pro specific and not due to removal of a hydrogen bond stabilizing the local $\beta$ sheet; instead, the decrease of channel gating likely stemmed from a local structural disturbance at the $\delta / \alpha$ subunit interface, or in the hydrophobic core of the $\delta$ subunit, or both.

Pro substitution of residues aligning with $\delta L 42$ in other subunits. To determine whether the effects of $\delta \mathrm{L} 42 \mathrm{P}$ are subunit specific, we mutated the corresponding Leu to Pro in the $\varepsilon, \alpha$, and $\beta$ subunits and recorded single-channel currents elicited by a range of ACh concentrations. Mutation of the $\varepsilon$ subunit decreased the mean duration of the major long component of bursts by approximately $50 \%$ (Figure 6 and Table 3), reduced $\mathrm{P}_{\text {open }}$ to a lesser extent than mutation of the $\delta$ subunit (Figure $7 C$ ), and attenuated the channel gating equilibrium constant 4-fold (Table 4). Mutation of the $\beta$ subunit had a minor effect on mean burst duration (Table 3 ) but had no effect on $\mathrm{P}_{\text {open }}$ (Figure $7 \mathrm{C}$ ) or on the channel gating equilibrium constant (Table 4). In striking contrast, mutation of the $\alpha$ subunit prolonged the mean duration of the longest component of bursts approximately 4 fold (Figure 6 and Table 3). The overall results indicate that although Leu is conserved and present at positions equivalent to $\delta \mathrm{L} 42$ in the other 3 subunits, the functional contributions of Leu depend on the subunit.

Pro mutations of residues adjacent to $\delta L 42$. To determine whether the effects of the $\delta \mathrm{L} 42 \mathrm{P}$ mutation were specific to its position in the local $\beta$ strand, we performed Pro scanning mutagenesis of 2 residues upstream and 2 residues downstream of $\delta L 42$. We found that each mutation significantly reduced the mean duration of the major long component of bursts, showing the greatest decrease

\section{Figure 4}

Mutation analysis. (A) Multiple sequence alignments of the $\beta_{1}$, $\beta_{2}$, and $\beta_{4}$ strands of AChR subunits. L42 is conserved in all human AChR subunits and in $\delta$ subunits of all species. Note the $\delta \mathrm{L} 42 \mathrm{P}, \delta 158 \mathrm{~K}$, and $\delta \mathrm{V} 93 \mathrm{~L}$ in the $\beta_{1}, \beta_{2}$, and $\beta_{4}$ strands, respectively. (B) Family analysis. The parents and 2 sisters (all heterozygous for $\delta$ L42P; half-shaded symbols) of the proposita (closed circle; arrow) were asymptomatic.
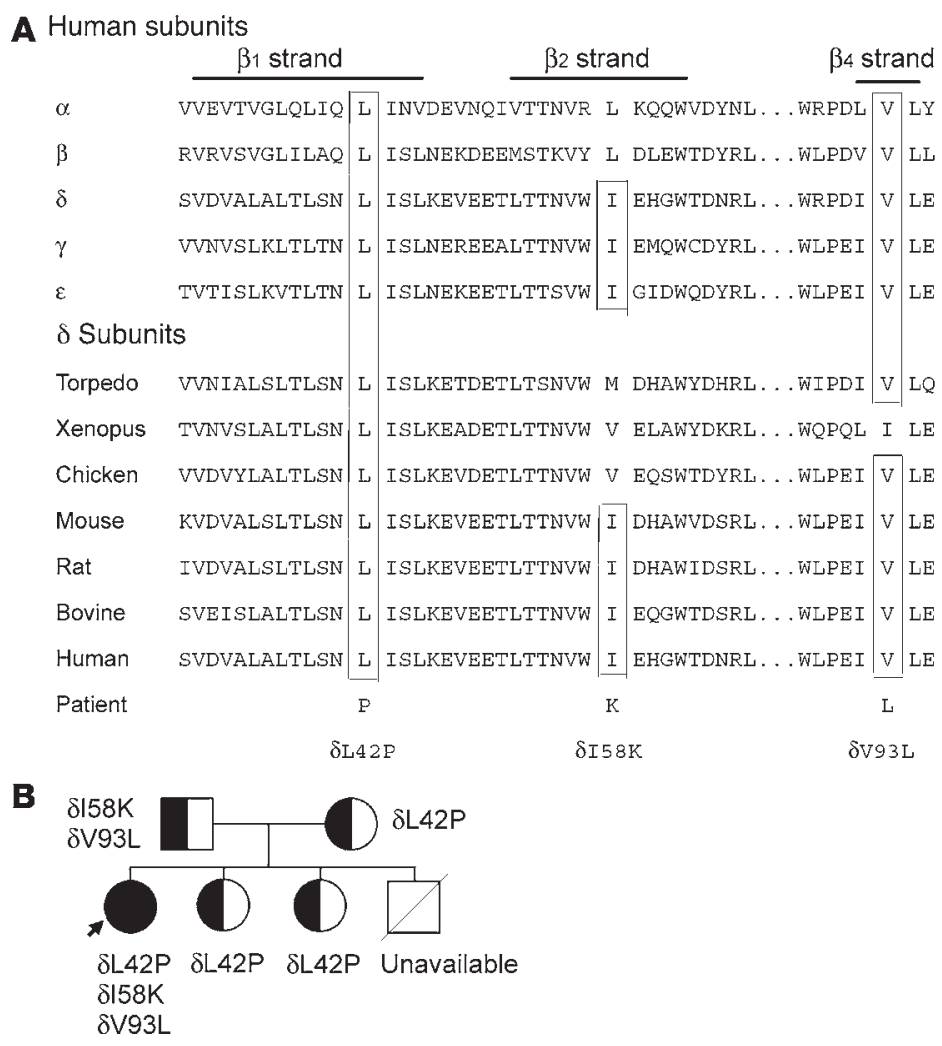
A

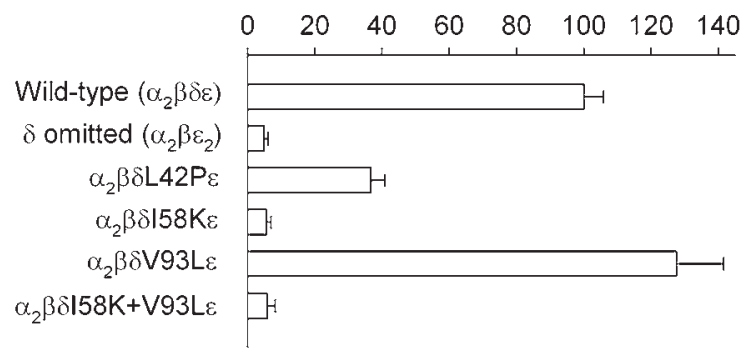

B

$\%$ of Control $\alpha \delta$ dimer $\alpha$-bgt bound

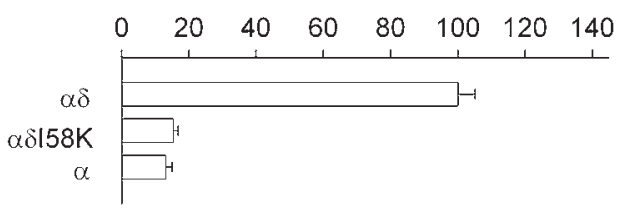

\section{Figure 5}

$\alpha$-bgt binding studies. (A) $\left[{ }^{125} \mathrm{I}\right] \alpha$-bgt binding to surface receptors on intact HEK cells transfected with the indicated AChR subunits. The results were normalized to results from $\alpha$-bgt binding to wild-type AChR $\left(\alpha_{2} \beta \delta \varepsilon\right)$ and represent mean \pm SD of 3-6 experiments. (B) Total $\alpha$-bgt binding to saponin-permeabilized cells transfected with the indicated subunit cDNAs. Amounts of bound $\left[{ }^{125} \mathrm{I}\right] \alpha$-bgt were normalized to that measured for the wild-type dimer $(\alpha \delta)$. with $\delta$ N41P (Table 3 ). Thus, over a span of 4 consecutive residues within the lower $\beta_{1}$ strand of the $\delta$ subunit, substitution of Pro attenuates receptor activation.

Mutant cycle analysis. The $\delta$ L42P mutation is located near the region of contact between the $\alpha$ and $\delta$ subunits (Figure 9A), suggesting that the mutation may alter intersubunit communication essential for rapid channel gating. In fact, a recent study showed that residues in this region, $\alpha \mathrm{Y} 127$ in the $2 \alpha$ subunits and $\delta \mathrm{N} 41$ and $\varepsilon N 39$ in the opposing $\delta$ and $\varepsilon$ subunits, are required for rapid channel gating, and further, that the functional contributions of each residue depend on the partner residue (15). This residue interdependence was quantified in terms of free energy of interresidue coupling using the method of mutant cycle analysis (See Methods and refs. 17,18 ). The presence of $\delta$ L $42 \mathrm{P}$ adjacent to $\delta$ N41 suggests that the patient mutation impedes channel opening by disrupting intersubunit communication mediated by $\delta$ N41 and $\alpha$ Y 127. Thus, to determine whether the functional consequences of $\delta$ L42P depend on $\alpha Y 127$ we used mutant cycle analysis. To generate the mutant cycle, we measured the diliganded channel gating equilibrium constant, $\theta_{2}$, for each receptor species, computed the free energy of gating according to $-R T \ln \theta_{2}$ (where $R$ is the gas constant and $T$ is the absolute temperature), and generated a 2-dimensional mutant cycle composed of gating free energies for

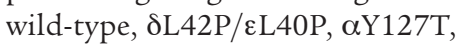
and $\alpha \mathrm{Y} 127 \mathrm{~T} / \delta \mathrm{L} 42 \mathrm{P} / \varepsilon L 40 \mathrm{P}$ AChRs (Figure 9B). For this mutant cycle, the interresidue coupling free energy of $3.9 \mathrm{kcal} / \mathrm{mol}$ exceeded the thermal free energy (RT, 0.58 $\mathrm{kcal} / \mathrm{mol}$ ), and approached the value of $5.8 \mathrm{kcal} / \mathrm{mol}$ obtained for the previously described mutant cycle composed of the mutations $\alpha Y 127 T, \delta N 41 A$, and $\varepsilon$ N39A. The
Table 3

Burst durations of wild-type and mutant AChRs in HEK cells

observation of a large interresidue coupling energy alone does not necessarily mean the residues under analysis couple through direct contact. In fact, $\delta$ L42 does not directly contact $\alpha$ Y 127, but rather the adjacent residue, $\delta \mathrm{N} 41$, does. Thus, $\delta \mathrm{L} 42 \mathrm{P}$ likely alters the local protein backbone so that interaction between $\delta \mathrm{N} 41$ and $\alpha Y 127$ is weakened.

To further examine the structural origin of the large coupling free energy, we cast 3 more 2-dimensional mutant cycles (Figure

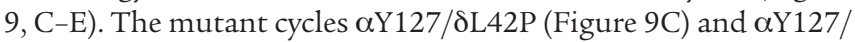
$\varepsilon L 40 P$ (Figure 9D) exhibited approximately equal coupling free energies of 2.2 and $1.6 \mathrm{kcal} / \mathrm{mol}$, respectively. Thus, at both the $\alpha-\delta$ and $\alpha-\varepsilon$ subunit interfaces, these residue pairs were required for rapid channel gating; the sum of coupling energies for the 2 cycles was $3.8 \mathrm{kcal} / \mathrm{mol}$, which approached the coupling energy for the overall cycle encompassing residues at both binding sites, indicating that the 2 subunit interfaces contribute independently to

\begin{tabular}{lccc}
\hline & & & \\
& & & \\
& & & \\
AChR & $\left(\mathrm{a}_{1}\right)$ & $\tau_{2}\left(\mathrm{a}_{2}\right)$ & $\tau_{3}\left(\mathrm{a}_{3}\right)$ \\
Wild-type & $0.04 \pm 0.002^{A}(0.24 \pm 0.02)$ & $0.47 \pm 0.06(0.21 \pm 0.03)$ & $3.31 \pm 0.12(0.58 \pm 0.04)$ \\
$\delta L 42 P$ & $0.18 \pm 0.04(0.69 \pm 0.02)$ & $0.76 \pm 0.23(0.31 \pm 0.02)$ & \\
$\delta V 93 L$ & $0.12 \pm 0.04 \mathrm{~B}(0.14 \pm 0.02)$ & $1.41 \pm 0.30(0.4 \pm 0.05)$ & $4.83 \pm 0.44(0.52 \pm 0.07)$ \\
$\delta L 42 G$ & $0.07 \pm 0.011(0.55 \pm 0.06)$ & $0.38 \pm 0.02(0.42 \pm 0.08)$ & \\
$\delta L 42 D$ & $0.16 \pm 0.02(0.73 \pm 0.04)$ & $0.63 \pm 0.31(0.27 \pm 0.04)$ & \\
$\delta L 42 \mathrm{~K}$ & $0.08 \pm 0.01(0.56 \pm 0.03)$ & $0.43 \pm 0.02(0.44 \pm 0.03)$ & \\
$\varepsilon L 40 P$ & $0.06 \pm 0.01(0.31 \pm 0.03)$ & $0.23 \pm 0.04(0.59 \pm 0.03)$ & $1.71 \pm 0.14(0.1 \pm 0.01)$ \\
$\beta L 40 P$ & $0.48 \pm 0.10(0.50 \pm 0.10)$ & $2.27 \pm 0.08(0.50 \pm 0.10)$ & \\
$\alpha L 40 P$ & $0.11 \pm 0.03(0.22 \pm 0.07)$ & $1.67 \pm 0.58(0.41 \pm 0.05)$ & $12.98 \pm 0.90(0.36 \pm 0.06)$ \\
$\delta S 40 P$ & $0.17(0.23)$ & $0.72(0.53)$ & \\
$\delta N 41 P$ & $0.074 \pm 0.01(0.37 \pm 0.02)$ & $0.61 \pm 0.03(0.63 \pm 0.02)$ & \\
$\delta$ I43P & $0.030 \pm 0.02(0.24 \pm 0.07)$ & $0.69 \pm 0.07(0.76 \pm 0.1)$ & \\
$\delta S 44 P$ & $0.024 \pm 0.001(0.21 \pm 0.04)$ & $0.35 \pm 0.03(0.64 \pm 0.04)$ & $2.05 \pm 0.54 \mathrm{C}(0.15 \pm 0.03)$
\end{tabular}

Twenty-one patches for wild-type, 5 for $\delta$ V93L, 4 for $\beta$ L40P and $\alpha$ L40P, multiple combined patches for $\delta S 40 P$, and 3 patches for all other AChRs were analyzed. Values indicate means $\pm S E M . \tau_{n}$ and $a_{n}$ indicate time constants and fractional histogram areas. $A C h=50 \mathrm{nM}$; membrane potential $=-80 \mathrm{mV}$; bandwidth $=11.7 \mathrm{kHz}$. A,B,CNot detected at 3, 2, and 1 patches, respectively. 


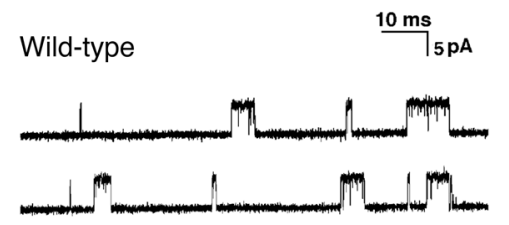

$\delta L 42 P$

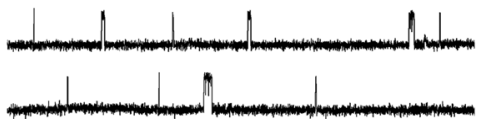

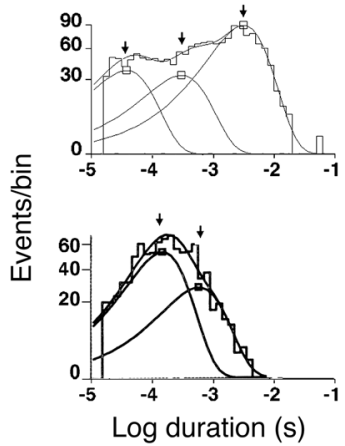
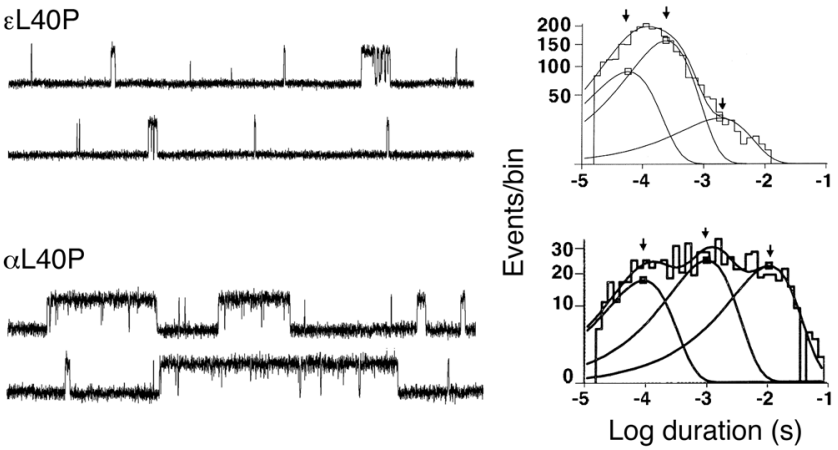

Figure 6

Single-channel currents elicited by $50 \mathrm{nM}$ ACh from HEK cells expressing wild-type and mutant AChRs. Left: Representative channel openings, shown as upward deflections. Right: Logarithmically binned burst-duration histograms fitted to the sum of exponentials. Arrows indicate mean durations of burst components.

rapid and efficient channel gating. The mutant cycle $\delta \mathrm{L} 42 \mathrm{P} / \varepsilon L 40 \mathrm{P}$ revealed a low coupling energy of $0.7 \mathrm{kcal} / \mathrm{mol}$, indicating $\delta \mathrm{L} 42 \mathrm{P}$ and $\varepsilon L 40 \mathrm{P}$ are independent in contributing to gating (Figure $9 \mathrm{E}$ ). Thus, although $\delta L 42 \mathrm{P}$ and $\varepsilon \mathrm{L} 40 \mathrm{P}$ are independent, their contributions to channel gating depend on the juxtaposed $\alpha \mathrm{Y} 127$ of the neighboring $\alpha$ subunit.

\section{Discussion}

We identify 3 mutations in the AChR $\delta$ subunit from a patient with moderately severe to severe myasthenic symptoms since birth. One mutation, $\delta \mathrm{V} 93 \mathrm{~L}$ has no appreciable kinetic effects and allows for robust AChR expression in HEK cells. The second mutation on the same allele, $\delta \mathrm{I} 58 \mathrm{~K}$, prevents expression of the AChR

\section{A Wild-type}

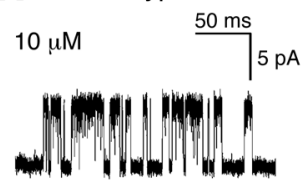

$30 \mu \mathrm{M}$

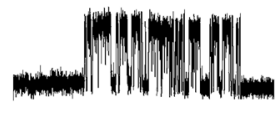

$300 \mu \mathrm{M}$

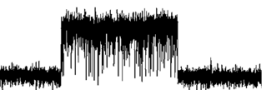

B $\delta L 42 \mathrm{P}$

$3 \mu \mathrm{M}$
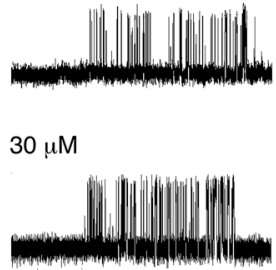

$300 \mu \mathrm{M}$

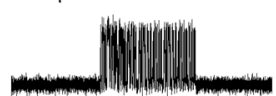

Closed
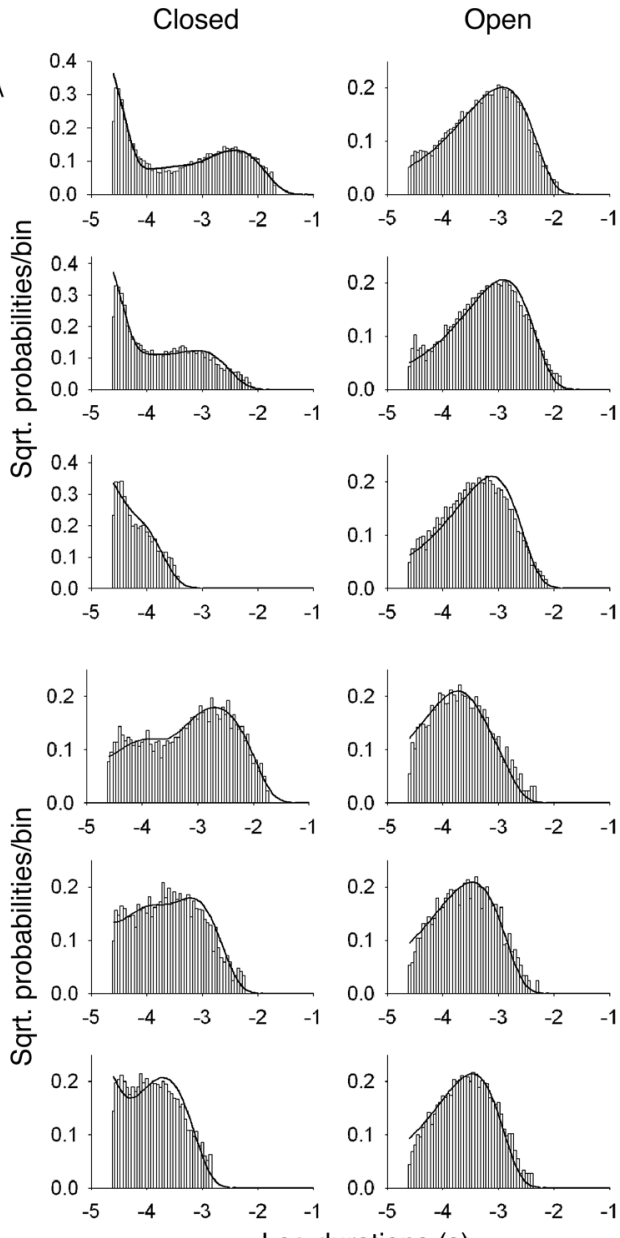

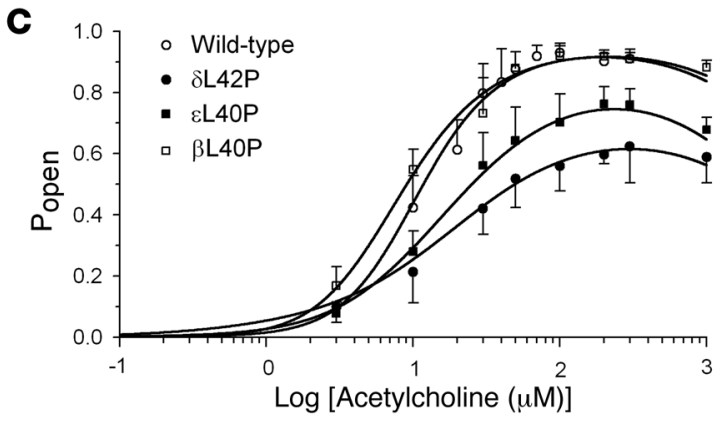

Figure 7

Activation kinetics of wild-type and $\delta$ L42P AChR and open channel probabilities. (A and B) Left: Representative singlechannel currents at the indicated ACh concentrations recorded from HEK cells expressing the indicated AChRs. Currents are shown as upward deflections; bandwidth, $10 \mathrm{kHz}$. Center and right: Histograms of closed and open durations corresponding to each ACh concentration are shown with the probability density functions (smooth curves) generated from a global fit of the scheme to dwell times obtained for the entire range of $\mathrm{ACh}$ concentrations. Fitted rate constants are shown in Table 4. On the $y$ axes, each histogram entry is the probability of occurrence on a square root (Sqrt.) scale. (C) $\mathrm{P}_{\text {open }}$ as function of $\mathrm{ACh}$ concentration. Symbols and vertical lines indicate means $\pm S D$. Smooth curves indicate the $P_{\text {open }}$ predicted by the fitted rate constants shown in Table 4. 


$$
\begin{aligned}
& \mathbf{A R}^{*} \mathbf{A}_{2} \mathbf{R}^{*} \underset{\beta_{1}}{\stackrel{k_{+b}}{\rightleftarrows}} \mathbf{A}_{2} \mathbf{R}_{\mathbf{B}} \\
& \mathbf{A}+\mathbf{R} \underset{\alpha_{1}}{\stackrel{k_{+1}}{\rightleftharpoons}} \mathbf{A} \mathbf{R}+\mathbf{A} \underset{\beta_{2}}{\stackrel{k+2}{\rightleftarrows} \|_{\alpha_{2}}} \mathbf{A}_{2} \mathbf{R}
\end{aligned}
$$

Figure 8

Kinetic scheme for AChR activation. AChR activation involves the reversible binding of 2 molecules of agonist $(A)$ to the AChR in the resting, closed state $(R)$, followed by reversible formation of the open state $\left(R^{*}\right)$. High concentrations of ACh block the open channel, producing a nonconducting blocked state $\left(R_{B}\right)$. Rate constants are indicated next to each arrow.

on the cell surface and is essentially a null mutation. Thus, the third mutation, $\delta$ L42P, determines the phenotype. $\delta$ L42P enables AChR expression, although at reduced levels, but it decreases gating efficiency 13-fold. Rate constants underlying activation of the $\delta$ L42P AChR (Table 4) predict a mean burst duration of $0.7 \mathrm{~ms}$, close to that measured for bursts elicited by a low ACh concentration (Table 3). This value predicts a 5-fold faster decay of postsynaptic currents at patient than at normal EPs. The activation rate constants also predict that the probability that a diliganded AChR will open during synaptic transmission is decreased from 0.84 to 0.53 . Thus, the synaptic response produced by an impulse of ACh is reduced by approximately $60 \%$ relative to that at normal EPs. The amplitude of the synaptic response is additionally curtailed by reduced expression of the $\delta$ L42P AChR and by the simplified junctional folds that decrease the input resistance of the post-synaptic membrane (19). Thus, the safety margin of neuromuscular transmission is compromised by the combined effects of EP AChR deficiency, altered EP geometry, reduced opening probability of the available AChRs, and abnormally fast decay of the synaptic current.

We also find that the consequences of $\delta \mathrm{L} 42 \mathrm{P}$ are not Pro specific because substitution with oppositely charged Asp and Lys residues, or with the small and flexible Gly residue, has similar kinetic effects. Pro substitutions along the local protein chain ( $\delta \mathrm{N} 41$, $\delta I 43$, and $\delta$ S44) mimic the effects of $\delta L 42 \mathrm{P}$, indicating that a span of at least 4 residues in the $\beta_{1}$ strand of the $\delta$ subunit is critical for maintaining rapid and efficient gating. Mutation of residues that align with $\delta L 42$ in the $\varepsilon, \beta$, and $\alpha$ subunits impede, fail to alter, or enhance gating. Therefore, the effects of the mutation are subunit specific. Finally, using mutant cycle analysis, we show that $\delta \mathrm{L} 42$ and $\varepsilon L 40$ contribute to an intersubunit linkage required for rapid and efficient channel gating. The $\delta \mathrm{L} 42 \mathrm{P}$ patient mutation likely causes a local structural perturbation that alters the intersubunit linkage of the adjacent $\delta \mathrm{N} 41$ with the juxtaposed $\alpha \mathrm{Y} 127$.

Although the identified Leu in the $\beta_{1}$ strand is conserved at equivalent positions of the $\alpha, \beta$, $\varepsilon$, and $\delta$ subunits, their contributions to AChR activation are subunit specific and have different functional consequences. These differences, in turn, may owe to the presence of different residues in the vicinity of the equivalent Leu residues in the different subunits. L42 in the $\delta$ subunit and

Table 4

Activation kinetics of wild-type and mutant AChRs expressed in HEK cells

\begin{tabular}{|c|c|c|c|c|c|c|c|c|c|c|c|c|c|c|c|}
\hline AChR & $k_{+1}$ & $k_{-1}$ & $K_{1} / \mu \mathrm{M}$ & $k_{+2}$ & $k_{-2}$ & $K_{2} / \mu \mathrm{M}$ & $\beta_{2}$ & $\alpha_{2}$ & $\theta_{1}$ & $\beta_{2}$ & $\alpha_{2}$ & $\theta_{2}$ & $k_{+b}$ & $k_{-b}$ & $K_{B} / \mathrm{mM}$ \\
\hline Wild-type & $\begin{array}{l}98 \\
\pm 7\end{array}$ & $\begin{array}{l}1,817 \\
\pm 185\end{array}$ & 19 & $\begin{array}{l}86 \\
\pm 2\end{array}$ & $\begin{array}{c}10,449 \\
\pm 186\end{array}$ & 121 & $\begin{array}{l}191 \\
\pm 16\end{array}$ & $\begin{array}{l}3,052 \\
\pm 276\end{array}$ & 0.06 & $\begin{array}{r}56,290 \\
\pm 1,500\end{array}$ & $\begin{array}{c}2,223 \\
\pm 75\end{array}$ & 25 & $\begin{array}{l}90 \\
\pm 6\end{array}$ & $\begin{array}{l}144,500 \\
\pm 2,515\end{array}$ & 1.61 \\
\hline$\delta L 42 P$ & $\begin{array}{r}193 \\
\pm 51\end{array}$ & $\begin{array}{r}139 \\
\pm 66\end{array}$ & 0.7 & $\begin{array}{l}96 \\
\pm 6\end{array}$ & $\begin{array}{l}6,070 \\
\pm 362\end{array}$ & 63 & $\begin{array}{l}438 \\
\pm 37\end{array}$ & $\begin{array}{l}6,919 \\
\pm 334\end{array}$ & 0.06 & $\begin{array}{l}6,770 \\
\pm 146\end{array}$ & $\begin{array}{l}3,015 \\
\pm 37\end{array}$ & 2 & $\begin{array}{l}44 \\
\pm 6\end{array}$ & $\begin{array}{l}143,410 \\
\pm 4,682\end{array}$ & 3.26 \\
\hline$\delta L 42 G$ & $\begin{array}{l}101 \\
\pm 29\end{array}$ & $\begin{array}{r}115 \\
\pm 48\end{array}$ & 1 & $\begin{array}{l}153 \\
\pm 7\end{array}$ & $\begin{array}{c}10,525 \\
\pm 502\end{array}$ & 69 & $\begin{array}{l}111 \\
\pm 12\end{array}$ & $\begin{array}{c}11,150 \\
\pm 760\end{array}$ & 0.01 & $\begin{array}{l}4,740 \\
\pm 85\end{array}$ & $\begin{array}{c}3,980 \\
\pm 39\end{array}$ & 1 & $\begin{array}{c}7 \\
\pm 1\end{array}$ & $\begin{array}{r}58,090 \\
\pm 4,340\end{array}$ & 8.30 \\
\hline$\delta L 42 D$ & $\begin{array}{c}80 \\
\pm 16\end{array}$ & $\begin{array}{l}20 \\
\pm 8\end{array}$ & 0.3 & $\begin{array}{l}135 \\
\pm 4\end{array}$ & $\begin{array}{l}9,990 \\
\pm 336\end{array}$ & 74 & $\begin{array}{l}97 \\
\pm 6\end{array}$ & $\begin{array}{l}8,522 \\
\pm 538\end{array}$ & 0.01 & $\begin{array}{l}5,820 \\
\pm 118\end{array}$ & $\begin{array}{l}3,140 \\
\pm 30\end{array}$ & 2 & $\begin{array}{l}54 \\
\pm 3\end{array}$ & $\begin{array}{l}143,440 \\
\pm 2,520\end{array}$ & 2.66 \\
\hline$\delta L 42 K$ & $\begin{array}{l}671 \\
\pm 63\end{array}$ & $\begin{array}{l}4,540 \\
\pm 641\end{array}$ & 7 & $\begin{array}{l}293 \\
\pm 18\end{array}$ & $\begin{array}{c}13,390 \\
\pm 670\end{array}$ & 46 & $\begin{array}{l}1,490 \\
\pm 168\end{array}$ & $\begin{array}{c}18,085 \\
\pm 727\end{array}$ & 0.08 & $\begin{array}{c}13,080 \\
\pm 312\end{array}$ & $\begin{array}{l}6,065 \\
\pm 113\end{array}$ & 2 & $\begin{array}{c}7 \\
\pm 1\end{array}$ & $\begin{array}{l}71,280 \\
\pm 8,190\end{array}$ & 10.18 \\
\hline$\varepsilon \mathrm{L} 40 \mathrm{P}$ & $\begin{array}{r}199 \\
\pm 32\end{array}$ & $\begin{array}{c}595 \\
\pm 162\end{array}$ & 3 & $\begin{array}{r}79 \\
\pm 5\end{array}$ & $\begin{array}{l}8,520 \\
\pm 434\end{array}$ & 108 & $\begin{array}{l}200 \\
\pm 24\end{array}$ & $\begin{array}{l}3,510 \\
\pm 182\end{array}$ & 0.06 & $\begin{array}{l}6,815 \\
\pm 235\end{array}$ & $\begin{array}{l}1,220 \\
\pm 21\end{array}$ & 6 & $\begin{array}{l}39 \\
\pm 3\end{array}$ & $\begin{array}{l}111,670 \\
\pm 2,850\end{array}$ & 2.86 \\
\hline$\beta \mathrm{L} 40 \mathrm{P}$ & $\begin{array}{r}229 \\
\pm 33\end{array}$ & $\begin{array}{l}1,313 \\
\pm 207\end{array}$ & 6 & $\begin{array}{l}159 \\
\pm 7\end{array}$ & $\begin{array}{c}21,710 \\
\pm 754\end{array}$ & 137 & ND & ND & ND & $\begin{array}{r}28,240 \\
\pm 1,200\end{array}$ & $\begin{array}{l}1,106 \\
\pm 30\end{array}$ & 26 & $\begin{array}{r}13 \\
\pm 2\end{array}$ & $\begin{array}{l}103,260 \\
\pm 7,670\end{array}$ & 7.94 \\
\hline$\alpha \mathrm{Y} 127 \mathrm{~T}$ & ND & ND & ND & ND & ND & ND & ND & ND & ND & $\begin{array}{l}182 \\
\pm 2\end{array}$ & $\begin{array}{c}3,568 \\
\pm 46\end{array}$ & 0.05 & $\begin{array}{r}14 \\
\pm 1\end{array}$ & $\begin{array}{r}66,020 \\
\pm 3,060\end{array}$ & 4.72 \\
\hline $\begin{array}{l}\alpha Y 127 T+ \\
\delta L 42 P\end{array}$ & $\begin{array}{r}150 \\
\pm 39\end{array}$ & $\begin{array}{l}1,182 \\
\pm 393\end{array}$ & 8 & $\begin{array}{r}195 \\
\pm 22\end{array}$ & $\begin{array}{r}12,160 \\
\pm 1,330\end{array}$ & 62 & $\begin{array}{c}44 \\
\pm 11\end{array}$ & $\begin{array}{c}13,674 \\
\pm 779\end{array}$ & 0.003 & $\begin{array}{l}1,210 \\
\pm 23\end{array}$ & $\begin{array}{c}7,540 \\
\pm 74\end{array}$ & 0.16 & $\begin{array}{l}11 \\
\pm 1\end{array}$ & $\begin{array}{c}67,221 \\
\pm 4,129\end{array}$ & 6.11 \\
\hline $\begin{array}{c}\alpha Y 127 T+ \\
\varepsilon L 40 P\end{array}$ & ND & ND & ND & $\begin{array}{l}50 \\
\pm 9\end{array}$ & $\begin{array}{l}4,900 \\
\pm 927\end{array}$ & 98 & $\begin{array}{l}102 \\
\pm 4\end{array}$ & $\begin{array}{c}10,050 \\
\pm 348\end{array}$ & 0.01 & $\begin{array}{l}707 \\
\pm 20\end{array}$ & $\begin{array}{l}3,735 \\
\pm 51\end{array}$ & 0.19 & $\begin{array}{r}14 \\
\pm 2\end{array}$ & $\begin{array}{r}71,760 \\
\pm 6,135\end{array}$ & 5.13 \\
\hline $\begin{array}{c}\delta L 42 P+ \\
\varepsilon L 40 P\end{array}$ & ND & ND & ND & $\begin{array}{l}368 \\
\pm 38\end{array}$ & $\begin{array}{l}1,225 \\
\pm 141\end{array}$ & 3 & ND & ND & ND & $\begin{array}{r}885 \\
\pm 11\end{array}$ & $\begin{array}{c}5,965 \\
\pm 53\end{array}$ & 0.15 & $\begin{array}{c}9 \\
\pm 1\end{array}$ & $\begin{array}{r}61,360 \\
\pm 5,850\end{array}$ & 6.82 \\
\hline $\begin{array}{l}\alpha Y 127 T+ \\
\delta L 42 P+ \\
\varepsilon L 40 P\end{array}$ & $\begin{array}{l}82 \\
\pm 8\end{array}$ & $\begin{array}{r}189 \\
\pm 56\end{array}$ & 2 & $\begin{array}{l}368 \\
\pm 55\end{array}$ & $\begin{array}{r}12,060 \\
\pm 1,710\end{array}$ & 33 & ND & ND & ND & $\begin{array}{l}1,820 \\
\pm 45\end{array}$ & $\begin{array}{l}8,460 \\
\pm 104\end{array}$ & 0.22 & $\begin{array}{c}6 \\
\pm 1\end{array}$ & $\begin{array}{r}45,990 \\
\pm 8,050\end{array}$ & 7.67 \\
\hline
\end{tabular}



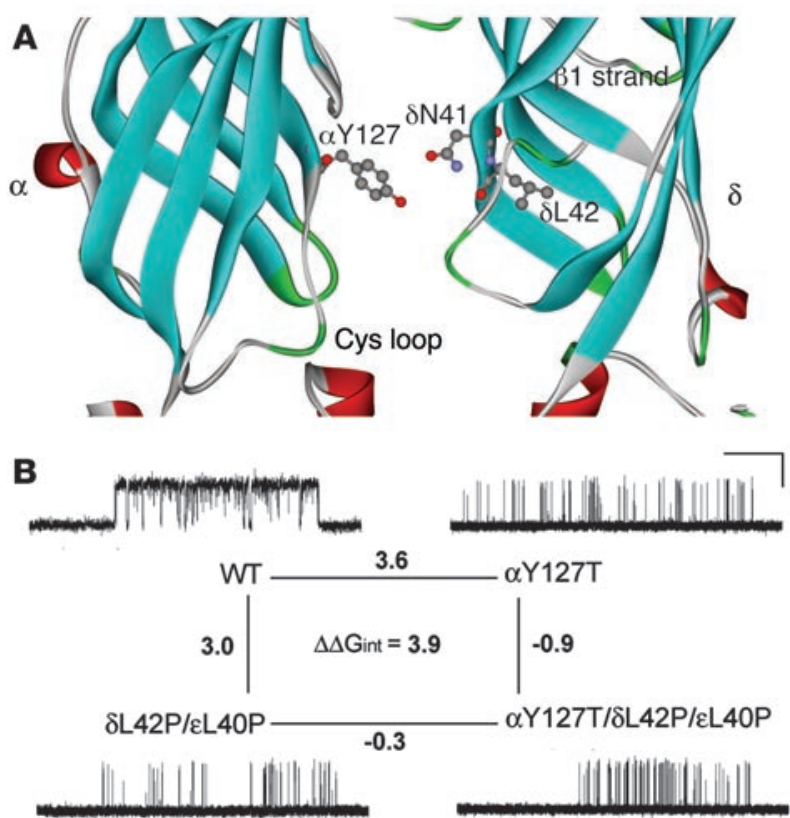

C

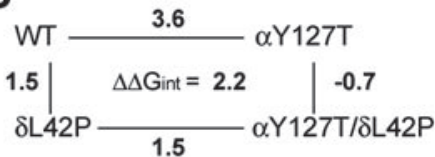

D
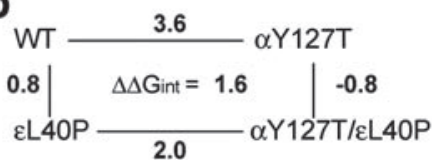

E

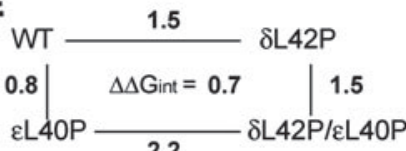

Figure 9

Structural model of the AChR $\alpha$ and $\delta$ subunits and mutant cycle analyses. (A) An enlarged view of the coupled intersubunit residues $\alpha Y 127$ and $\delta N 41$ in the structural model of the Torpedo AChR (Protein Data Bank code 2BG9). (B) A mutant cycle for the mutations $\alpha$ Y127T, $\delta L 42 P$, and $\varepsilon$ L40P. Single-channel currents correspond to each AChR elicited by $100 \mu \mathrm{M}$ ACh, as in Figure 6 . Changes in gating free energy along each limb of the cycle are shown, and the overall coupling free energy $\left(\Delta \Delta \mathrm{G}_{\mathrm{int}}\right)$ in units of $\mathrm{kcal} / \mathrm{mol}$ computed from $-\mathrm{RT} \ln \left[\left(\theta_{w w} \theta_{\mathrm{mm}}\right) /\left(\theta_{w m} \theta_{\mathrm{mw}}\right)\right]$, where $\theta(\beta / \alpha)$ is a gating equilibrium constant for diliganded receptors for wild-type, single-mutant, or double-mutant AChRs (Table 4). Horizontal bar indicates $20 \mathrm{~ms}$ for wild-type and $100 \mathrm{~ms}$ for mutant AChRs. Vertical bar indicates $5 \mathrm{pA}$. (C-E) Mutant cycles for the indicated mutations are shown, as described in $\mathbf{B}$.

L40 in the $\varepsilon$ subunit are each adjacent to the key Asn residue that spans the subunit interface (see Figure 9A) and mediates intersubunit interactions with $\alpha \mathrm{Y} 127$ that are essential for rapid and efficient channel gating (15). None of the other subunit interfaces contain a Tyr/Asn linkage, suggesting the lower $\beta_{1}$ strands of the $\alpha, \delta$, and $\varepsilon$ subunits contribute uniquely to channel gating.

To our knowledge, before the current study, it was not known whether residues at equivalent positions at the 3 subunit interfaces not involved in ligand binding contribute to channel gating. However, by examining the equivalent Leu residue in the $\alpha$ subunit, we find that the non-ligand binding interfaces between the $\alpha$ and $\varepsilon$ subunits and between the $\alpha$ and $\beta$ subunits contribute to channel gating, but in a novel manner; the mutation $\alpha \mathrm{L} 40 \mathrm{P}$ enhances rather than attenuates channel gating. Thus, residue differences at these non-ligand binding interfaces emerge as candidates for intersubunit linkages required for channel gating and await further investigation.

\section{Methods}

Muscle specimens. Intercostal muscle specimens were obtained intact from origin to insertion from patient and control subjects without muscle disease undergoing thoracic surgery. All human studies were in accordance with the guidelines of, and were approved by, the Institutional Review Board of the Mayo Clinic. Each patient provided informed consent to participate in the study.

$\mathrm{AChR}$ and ACh were detected in cryostat sections by 2-color fluorescence (20). EPs were localized for EM and analyzed by the established methods (21). Peroxidase-labeled $\alpha$-bgt was used for the ultrastructural localization of AChR (22). The number of AChRs per EP was measured with [125I] $\alpha$-bgt (23).

Electrophysiology of muscle specimens. Recordings of EP potentials (EPPs) and EP currents (EPCs) and estimates of the number of transmitter quanta released by nerve impulse were performed as described elsewhere $(23,24)$, except that the amplitude of the MEPPs and MEPCs were estimated from the quantal components of the EPP and EPC, respectively (25).

Mutation analysis. We directly sequenced $\operatorname{AChR} \alpha, \beta, \delta$, and $\varepsilon$ subunit genes using genomic DNA. The mutations were traced with allele-specific PCR in family members and in 200 normal alleles of 100 unrelated controls.

Construction and expression of wild-type and mutant AChRs. Sources of human $\alpha, \beta, \varepsilon$, and $\delta$ subunit cDNAs were as previously described (26). All $4 \mathrm{cDNAs}$ were subcloned into the CMV-based expression vector pRBG4 for expression in HEK 293 cells (26). The artificial mutations were engineered into wild-type AChR subunit cDNAs in pRBG4 using the QuikChange SiteDirected Mutagenesis Kit (Stratagene). The presence of each mutation and absence of unwanted mutations was confirmed by sequencing the entire inserts. HEK cells were transfected with plasmids comprised of pRBG4- $\alpha$, $-\beta,-\delta$, and $-\varepsilon$, and pEGFP-N1 in a ratio of $2: 1: 1: 1: 1$, using FuGENE6 transfection reagent (Roche).

$\alpha$-bgt binding measurements. The total number of [ $\left.{ }^{125} \mathrm{I}\right] \alpha$-bgt sites on the surface of transfected HEK cells were determined as described elsewhere (26).

Patch-clamp recordings and single-channel kinetic analysis. Recordings were obtained in the cell-attached configuration at a membrane potential of $-80 \mathrm{mV}$ at $22^{\circ} \mathrm{C}$ and with bath and pipette solutions containing (in $\mathrm{mM}$ ): $\mathrm{KCl}, 142 ; \mathrm{NaCl}, 5.4 ; \mathrm{CaCl}_{2}, 1.8 ; \mathrm{MgCl}_{2}, 1.7$; HEPES, 10, pH 7.4 (26). Singlechannel currents were recorded using an Axopatch 200A amplifier (Axon Instruments) at a bandwidth of $50 \mathrm{kHz}$, digitized at 5 - $\mu$ s intervals using a 
Digidata 1322A (Axon Instruments) and recorded to hard disk using the program Clampex 8 (Axon Instruments). Records were analyzed at a uniform bandwidth of $11.7 \mathrm{kHz}$ for recordings at ACh concentrations of 50 $\mathrm{nM}$ and $10 \mathrm{kHz}$ for recordings at $3 \mu \mathrm{M}$ or above with TACx4.0.9 software (Bruxton). Dwell-time histograms were plotted on a logarithmic abscissa and fitted to the sum of exponentials by maximum likelihood (27).

To estimate rate constants underlying AChR activation, we employed desensitizing concentrations of ACh that cause events from a single channel to cluster into identifiable activation episodes (28). Clusters were identified as a series of closely spaced openings preceded and followed by closed intervals greater than a defined critical time. The critical time was determined by a method that misclassifies an equal number of events between 2 adjacent closed-time components (29). For each receptor, the critical time that provided the best fit for the closed-time histogram was chosen for the final analysis. Clusters with fewer than 5 openings were excluded from analysis. Individual clusters were examined for homogeneity by determining the mean $\mathrm{P}_{\text {open }}$ and open duration for each cluster, and clusters within $2 \mathrm{SDs}$ of the means were accepted for further analysis $(30,31)$. The resulting global set of open and closed dwell times of wild-type and mutant AChRs were analyzed using the program MIL (QuB suite; State University of New York, Buffalo), which uses an interval-based maximum likelihood method that also corrects for missed events (30). The kinetic analysis of wild-type and mutant receptors yielded a set of rate constants that were fitted to a scheme of receptor activation (see Figure 8).

For each type of AChR, single-channel dwell times obtained over a range of ACh concentrations were fitted simultaneously. Data were obtained over a range of ACh concentrations from 10 to $300 \mu \mathrm{M}$ for wild-type and $\alpha \mathrm{Y} 127 \mathrm{~T} /$ EL40P AChR, from 100 to $1,000 \mu \mathrm{M}$ for $\alpha \mathrm{Y} 127 \mathrm{~T} \mathrm{AChR}$, and from 3 to 1,000 $\mu \mathrm{M}$ for other AChRs; 1,562-11,250 (mean, 4,800) events were analyzed for each ACh concentration. The final set of rate constants was checked by superimposing probability density functions calculated from the rate constants on the experimental dwell time histograms and by the ability of the rate constants to predict burst length at low ACh concentrations $(32,33)$.

Mutant cycle analysis. To determine whether the functional contributions of 2 residues in the AChR, $\mathrm{X}$ and $\mathrm{Y}$, are interdependent, we employed the method of thermodynamic mutant cycle analysis, which examines the functional consequences of mutating residue $\mathrm{X}$ without and with mutation of residue $Y$. This method requires quantifying the free energy change associated with a given state change for the mutants $A C h R_{X}$, $\mathrm{AChR}_{\mathrm{Y}}$, and $\mathrm{AChR}_{\mathrm{XY}}$. In the case of the $\mathrm{AChR}$, the relevant state change is defined by the channel gating equilibrium constant of the diliganded receptor, $\theta_{2}$, which has an associated free energy change $\Delta G=-R T \ln \theta_{2}$. The changes in gating free energy due to the mutations $\mathrm{X}, \mathrm{Y}$, and $\mathrm{XY}$ relative to the wild-type are designated $\Delta \Delta \mathrm{G}_{\mathrm{X}}, \Delta \Delta \mathrm{G}_{\mathrm{Y}}$, and $\Delta \Delta \mathrm{G}_{\mathrm{XY}}$. These terms are related to the free energy of interresidue interaction, $\Delta \Delta \mathrm{G}_{\mathrm{INT}}$, as follows: $\Delta \Delta G_{X Y}=\Delta \Delta G_{X}+\Delta \Delta G_{Y}+\Delta \Delta G_{I N T}(17,18,34)$. Given this relationship and noting that the $\Delta \Delta \mathrm{Gs}$ for each mutant AChR equal $\Delta \mathrm{G}_{\mathrm{X}}-\Delta \mathrm{G}_{\mathrm{W}}$, then $\Delta \mathrm{G}_{\mathrm{Y}}-\Delta \mathrm{G}_{\mathrm{W}}, \Delta \mathrm{G}_{\mathrm{XY}}-\Delta \mathrm{G}_{\mathrm{W}}$, and $\Delta \Delta \mathrm{G}_{\mathrm{INT}}=-\mathrm{RT} \ln \left[\left(\theta_{2}(\mathrm{~W}) \theta_{2}(\mathrm{XY})\right) /\left(\theta_{2}(\mathrm{X}) \theta_{2}(\mathrm{Y})\right)\right]$, where $\theta_{2}$ is the measured channel gating equilibrium constant for wildtype (W) and mutant (X, Y, XY) AChRs.

Statistics. Patient and control values were compared by 2 -tailed Student's $t$ test. Standard error estimates of activation rate constant of wild-type and mutant receptors shown in Table 2 were computed by the MIL program from the curvature of the likelihood function at its maximum $(35,36)$ Differences were considered statistically significant at $P<0.05$.

\section{Acknowledgments}

This work was supported by NIH grants to A.G. Engel (NS-6277) and to S.M. Sine (NS-31744) and by a Muscular Dystrophy Association Grant to A.G. Engel. We thank Isabella Illa for patient referral.

Received for publication November 19, 2007, and accepted in revised form February 13, 2008.

Address correspondence to: Andrew G. Engel, Department of Neurology, Mayo Clinic, 200 First Street SW, Rochester, Minnesota 55905, USA. Phone: (507) 284-5102; Fax: (507) 284-5831; E-mail: age@mayo.edu.

Taku Fukuda's present address is: First Department of Internal Medicine, Nagasaki University Hospital, Nagasaki, Japan.

Kinji Ohno's present address is: Department of Neurogenetics, Nagoya University Graduate School of Medicine, Nagoya, Japan.
1. Engel, A.G., and Sine, S.M. 2005. Current understanding of congenital myasthenic syndromes. Curr. Opin. Pharmacol. 5:308-321.

2. Ohno, K., et al. 2001. Choline acetyltransferase mutations cause myasthenic syndrome associated with episodic apnea in humans. Proc. Natl. Acad. Sci. U. S. A. 98:2017-2022.

3. Ohno, K., Brengman, J.M., Tsujino, A., and Engel, A.G. 1998. Human endplate acetylcholinesterase deficiency caused by mutations in the collagenlike tail subunit (ColQ) of the asymmetric enzyme. Proc. Natl. Acad. Sci. U. S. A. 95:9654-9659.

4. Donger, C., et al. 1998. Mutation in the human acetylcholinesterase-associated gene, COLQ, is responsible for congenital myasthenic syndrome with end-plate acetylcholinesterase deficiency. Am. J. Hum. Genet. 63:967-975.

5. Engel, A.G., Ohno, K., and Sine, S.M. 2003. Sleuthing molecular targets for neurological diseases at the neuromuscular junction. Nat. Rev. Neurosci. 4:339-352.

6. Ohno, K., et al. 2002. Rapsyn mutations in humans cause endplate acetylcholine receptor deficiency and myasthenic syndrome. Am. J. Hum. Genet. 70:875-885.

7. Chevessier, F., et al. 2004. MUSK, a new target for mutations causing congenital myasthenic syndrome. Hum. Mol. Genet. 13:3229-3240.

8. Beeson, D., et al. 2006. Dok-7 mutations underlie a neuromuscular junction synaptopathy. Science. 313:1975-1978.

9. Tsujino, A., et al. 2003. Myasthenic syndrome caused by mutation of the SCN4A sodium channel. Proc. Natl. Acad. Sci. U. S. A. 100:7377-7382.

10. Galzi, J.L., Rvah, F., Bessis, A., and Changeux, J.-P. 1991. Functional architecture of the nicotinic acetylcholine receptor: from electric organ to brain. Annu. Rev. Pharmacol. Toxicol. 31:37-72.

11. Unwin, N. 2005. Refined structure of the nicotinic acetylcholine receptor at $4 \AA ̊$ resolution. J. Mol. Biol. 346:967-989.

12. Unwin, N., Miyazawa, A., Li, J., and Fujiyoshi, Y. 2002. Activation of the nicotinic acetylcholine receptor involves a switch in conformation of the $\alpha$ subunits. J. Mol. Biol. 319:1165-1176.

13. Sine, S.M., and Engel, A.G. 2006. Recent advances in Cys-loop receptor structure and function. Nature. 440:448-455.

14. Gay, E.A., and Yakel, J.L. 2007. Gating of nicotinic ACh receptors; new insights into structural transitions triggered by agonist binding that induce channel opening. J. Physiol. 584:727-733.

15. Mukhtasimova, N., and Sine, S.M. 2007. An intersubunit trigger of channel gating in the muscle nicotinic receptor. J. Neurosci. 27:4110-4119.

16. Keller, S.H., and Taylor, P. 1999. Determinants responsible for assembly of the nicotinic acetylcholine receptor. J. Gen. Physiol. 113:171-176.
17. Wells, J.A. 1990. Additivity of mutational effects in proteins. Biochemistry. 29:8509-8517.

18. Horovitz, A., and Fersht, A. 1990. Strategy for analyzing the co-operativity of intramolecular interactions in peptides and proteins. J. Mol. Biol. 214:613-617.

19. Martin, A.R. 1994. Amplification of neuromuscular transmission by postjunctional folds. Proc. $R$. Soc. Lond. B Biol. Sci. 258:321-326.

20. Fambrough, D.M., Engel, A.G., and Rosenberry, T.L. 1982. Acetylcholinesterase of human erythrocytes and neuromuscular junctions: homologies revealed by monoclonal antibodies. Proc. Natl. Acad. Sci. U. S. A. 79:1078-1082.

21. Engel, A.G. 1994. Quantitative morphological studies of muscle. In Myology. A.G. Engel and C. Franzini-Armstrong, editors. McGraw-Hill. New York, New York, USA. 1018-1045.

22. Engel, A.G., Lindstrom, J.M., Lambert, E.H., and Lennon, V.A. 1977. Ultrastructural localization of the acetylcholine receptor in myasthenia gravis and in its experimental autoimmune model. Neurology. 27:307-315.

23. Engel, A.G., Nagel, A., Walls, T.J., Harper, C.M., and Waisburg, H.A. 1993. Congenital myasthenic syndromes. I. Deficiency and short opentime of the acetylcholine receptor. Muscle Nerve. 16:1284-1292.

24. Uchitel, O., et al. 1993. Congenital myasthenic 
syndromes. II. A syndrome attributed to abnormal interaction of acetylcholine with its receptor. Muscle Nerve. 16:1293-1301.

25. Elmqvist, D., and Quastel, D.M.J. 1965. A quantitative study of end-plate potentials in isolated human muscle. J. Physiol. 178:505-529.

26. Ohno, K., et al. 1996. Congenital myasthenic syndrome caused by decreased agonist binding affinity due to a mutation in the acetylcholine receptor $\varepsilon$ subunit. Neuron. 17:157-170.

27. Sigworth, F.J., and Sine, S.M. 1987. Data transformation for improved display and fitting of single-channel dwell time histograms. Biophys. J. 52:1047-1054.

28. Sakmann, B., Patlak, J., and Neher, E. 1980. Single acetylcholine-activated channels show burst kinetics in the presence of desensitizing concentrations of agonist. Nature. 286:71-73.

29. Colquhoun, D., and Sakmann, B. 1985. Fast events in single channel currents activated by acetylcholine and its analogues at the frog muscle end-plate. J. Physiol. 369:501-557.

30. Qin, F., Auerbach, A., and Sachs, F. 1996. Estimating single-channel kinetic parameters from idealized patch-clamp data containing missed events. Biophys. J. 70:264-280.

31. Shen, X.-M., et al. 2003. Mutation causing severe myasthenia reveals functional asymmetry of AChR signature Cys-loops in agonist binding and gating. J. Clin. Invest. 111:497-505.

32. Colquhoun, D., and Hawkes, A.G. 1995. A Q-matrix cookbook: How to write only one program to calculate the single-channel and macroscopic predic- tions for any kinetic mechanism. In Single-channel recording. B. Sakmann and E. Neher, editors. Plenum Press. New York, New York, USA. 589-633.

33. Colquhoun, D., and Hawkes, A.G. 1995. The principles of the stochastic interpretation of ion channel mechanisms. In Single-channel recording. B. Sakmann and E. Neher, editors. Plenum Press. New York, New York, USA. 397-482.

34. Horovitz, A. 1996. Double-mutant cycles: a powerful tool for analyzing protein structure and function. Fold. Des. 1:R121-R126.

35. Qin, F., Auerbach, A., and Sachs, F. 1997. Maximum likelihood estimation of aggregated Markov process. Proc. Biol. Sci. 264:375-383.

36. Cox, D.R., and Miller, H.D. 1965. The theory of stochastic processes. Methuen. London, UK. 398 Pp. 